\title{
Role of Pharmacy Services in Accountable Care Organizations
}

\author{
Carrie H. Colla, PhD; Valerie A. Lewis, PhD; \\ Brendin R. Beaulieu-Jones; and Nancy E. Morden, MD, MPH
}

\begin{abstract}
BACKGROUND: The accountable care organization (ACO) model being adopted across the United States aims to improve patient care and reduce costs. Little is known about whether commercial ACO contracts include accountability for prescription drug spending or how ACOs are engaging outpatient pharmacies and managing prescription drug use.

OBJECTIVE: To explore how ACOs are addressing drug spending and pharmacy services-a potentially important determinant of quality and total spending.

METHODS: We used data from 2 waves of the National Survey of Accountable Care Organizations ( $\mathrm{N}=270$ ), a survey completed by ACOs that were established prior to July 2013. ACO executives were asked about ACO engagement of pharmacy services, pharmacy-related health information technology capabilities, and ACO accountability for prescription drug spending.
\end{abstract}

RESULTS: Among ACOs with commercial contracts, $77 \%$ reported being held responsible for prescription spending by their largest contract. Considering all ACOs (Medicare, Medicaid, and/or commercial contracts), $45 \%$ reported at least 1 contract included prescription drug spending responsibility. Nearly half of ACOs reported a formal relationship with a pharmacy; 26\% included a pharmacy within the AC0; and 19\% had contracted pharmacy services. On average, compared with those that do not, ACOs that engage pharmacies have a broader range of services and provider types, commercial and public contracts, and greater experience with payment reform.

CONCLUSIONS: Management of pharmacy services and prescription spending will likely influence commercial ACO contract success. Given the broad potential impact of prescription use on overall spending and quality, payers might encourage integration of pharmacy services in ACOs through prescribing quality and prescription spending performance measures.

J Manag Care Spec Pharm. 2015;21(4):338-44

Copyright $\odot 2015$, Academy of Managed Care Pharmacy. All rights reserved.

\section{What is already known about this subject}

Medicare accountable care organization (ACO) contracts do not yet include accountability for prescription spending, but little is known about whether commercial ACO contracts include accountability for prescription drug spending or how ACOs are engaging outpatient pharmacies and managing prescription drug use.

Prescription use varies considerably across regions in terms of volume, branded product selection, and spending, suggesting opportunities for increased efficiency.

Underuse, overuse, and misuse of prescription drugs, especially for patients with chronic conditions, can substantially influence nonprescription health care spending and outcomes.

\section{What this study adds}

This study provides a first look at the national landscape of ACOs and their efforts to engage pharmacies in the provision of health services.

The majority of ACOs with commercial contracts (77\%) are being held responsible for prescription spending.

Nearly half of ACOs report a formal relationship with a pharmacy: 26\% include a pharmacy within the ACO, and 19\% have contracted pharmacy services.

When compared with ACOs that do not formally engage pharmacies, ACOs with pharmacy relationships have a broader range of services and provider types, commercial and public contracts, and more experience with payment reform.

$\mathrm{P}$ rescription drugs are an important component of health care with the potential to affect overall spending and the quality of care directly and indirectly. Prescription drug spending accounted for $10 \%$ of national health expenditures in 2010 and is expected to account for almost $20 \%$ of the Medicare budget by 2020, ${ }^{1,2}$ There is considerable regional variation in prescription use in terms of volume, branded product selection, and spending, suggesting opportunities for increased efficiency. ${ }^{3-9}$ Underuse, overuse, and misuse of prescription drugs, especially for patients with chronic conditions,$^{10}$ can substantially influence nonprescription health care spending and outcomes. ${ }^{11-14}$ Appropriate use of prescription drugs can contribute to improving health, reducing downstream costs, and achieving many existing health care quality measures. ${ }^{15,16}$ The management of prescription services may thus be a key component of efforts aimed at reducing spending and improving quality-vital goals of health care reform policies.

In the past decade, providers, payers, and policymakers have expressed hope for the impact of accountable care organizations (ACOs) on health care cost and quality. ${ }^{17-19}$ Despite the important role of prescription drugs in determining overall health care spending, little is known about the management of prescription services and prescription spending in innovative payment contracts such as ACOs.

To explore how ACOs are addressing drug spending and pharmacy services, a potentially important determinant of quality and total spending, we analyzed data from a national survey of ACOs to provide the first comprehensive analysis of how ACOs are managing prescription drug services as part of their effort to succeed in the aims of these contracts. We 
examined the extent to which ACOs are responsible for prescription drug spending, ACO relationships with pharmacies, and ACO capability to monitor and manage prescription drug use. An understanding of these efforts will clarify the extent to which innovative payment contract participants are working to leverage drug management to improve care quality and achieve savings. Understanding ACO efforts to manage prescription services will facilitate future outcomes studies of diverse drug management strategies and will ultimately inform policies aimed at optimizing efficient prescription use to advance U.S. health and health care models. ${ }^{15}$

\section{Methods}

\section{Survey Design}

The National Survey of Accountable Care Organizations collected comprehensive information on ACOs and their development. The survey included questions on organizational characteristics, contract features, previous experience with payment reform, and health information technology capabilities. Cognitive testing of a sample of questions was completed by 7 organizations to determine whether the questions were clear and easy to answer by the respondent, and pilot testing of the complete instrument was done by 19 organizations. These organizations were chosen from a convenience sample based on their characteristics to ensure that a variety of ACO organizations could understand and respond to the survey questions. The survey was administered by phone or an online tool; nearly all respondents (98\%) completed the survey online. Our institutional review board approved the survey instrument and study protocol.

\section{Survey Population}

We defined an ACO as a group of providers collectively held accountable for the total cost and quality of care for a defined patient population. We identified all probable ACOs established by July 2013. ACOs that had a contract with either Medicare or Medicaid are publicly available; we identified ACOs with commercial payers contracts through multiple sources, including participation in ACO implementation or learning collaboratives, national surveys identifying ACOs, published ACO case studies, and public notices of ACO contracts (e.g., press releases).

We identified 292 organizations to include in the survey population for wave 1 (ACOs established by August 2012) and 220 for wave 2 (ACOs established by July 2013). ACOs with public payer contracts were verifiable and automatically considered eligible; eligibility of other organizations was determined using a set of screening questions at the beginning of the survey (see Appendix). A total of 270 eligible organizations completed the survey in 2 separate waves between October 2012 and May 2013 and between September 2013 and March 2014. The respondent at each organization was an executive or director-level administrator. Estimates of site eligibility and survey completeness were calculated to determine the response rate using American Association for Public Opinion Research methodology (which stratifies groups of potential respondents based on probability of eligibility). ${ }^{20}$ The response rate was $66 \%$.

\section{Measures}

The survey contained questions regarding the distinct services included in the calculation of total cost for which an ACO is responsible, including prescription drugs. Respondents were asked to answer with regard to their largest commercial ACO contract (i.e., that with the largest number of attributed patients). ACOs with public payer contracts only were not asked about services in the calculation of their total cost, as these standard contracts were publicly available.

The survey also included questions on organizational characteristics, including relationships with outpatient pharmacies and data capabilities. Specifically, respondents were asked to indicate the highest level of engagement their ACO has with an outpatient pharmacy; response options included (a) having a pharmacy within the ACO, (b) contracting with an outside pharmacy, and (c) having no formal relationship. Respondents were also asked a series of questions on health information technology infrastructure including capabilities associated with prescription drug management. Respondents were asked to characterize their capability to conduct the following: e-prescribe and confirm whether prescriptions have been filled; integrate inpatient and outpatient data (including medication data) from ACO providers as well as outside providers in an electronic health record; maintain a list of diagnoses and medications in the electronic health record; and provide patients with an electronic copy of health information and/or discharge instructions.

\section{Statistical Analysis}

We examined overall outcomes and stratified by contract type, specifically ACOs with a commercial contract $(n=140)$ and ACOs with a Medicare contract and no commercial contract $(n=111)$. ACOs with only a Medicaid contract $(n=19)$ were captured in both of these groups, and their responses were included in the overall analysis. Chi-squared tests were performed to determine the significance of differences between ACOs with commercial contract and those with a Medicare contract but no commercial contract.

In addition, we assessed differences in characteristics and capabilities of ACOs with an outpatient pharmacy (having a pharmacy or contracting with a pharmacy). We used bivariate analysis to assess the relationship between outpatient pharmacy engagement and specific ACO characteristics, including organizational characteristics (e.g., whether the ACO includes a hospital), contract features, and previous experience with payment reform. Significance of the bivariate association was assessed using either a chi-square test or a t-test, depending on the type of variable. 
TABLE 1 Pharmacy Engagement and Prescription Drug Management in ACOs: Overall and by Contract Type (Commercial, Medicare, Medicaid)

\begin{tabular}{|c|c|c|c|c|c|}
\hline & $\begin{array}{c}\text { All } \\
(\mathrm{N}=270)\end{array}$ & $\begin{array}{c}\text { Private }^{\mathrm{a}} \\
(\mathrm{n}=140,51.9 \%)\end{array}$ & $\begin{array}{c}\text { Medicare }^{\mathrm{b}} \\
(\mathrm{n}=111,41.1 \%)\end{array}$ & $\begin{array}{c}\text { Medicaidc } \\
(\mathrm{n}=19,7.0 \%)\end{array}$ & $P$ Value \\
\hline $\begin{array}{l}\text { At least } 1 \text { accountable care contract including pharmacy spending in } \\
\text { calculation of total cost (\%) }\end{array}$ & 45.2 & 76.8 & 1.8 & 90.0 & $<0.001$ \\
\hline \multicolumn{6}{|l|}{ Engagement with outpatient pharmacy (\%) } \\
\hline Pharmacy within the ACO & 26.4 & 31.1 & 15.8 & 50.0 & 0.001 \\
\hline Pharmacy contracted outside the ACO & 19.3 & 22.2 & 14.9 & 22.2 & \\
\hline \multicolumn{6}{|l|}{ Pharmacy-related health IT and data capabilities (\%) } \\
\hline Near complete ability to e-prescribe and confirm fill & 45.6 & 53.4 & 37.3 & 36.8 & 0.068 \\
\hline $\begin{array}{l}\text { Near complete ability to maintain a list of diagnoses and medications } \\
\text { in EHR }\end{array}$ & 54.4 & 59.8 & 51.0 & 36.8 & 0.109 \\
\hline $\begin{array}{l}\text { Near complete ability to integrate inpatient and outpatient data in } \\
\text { EHR, including medication data from ACO providers }\end{array}$ & 38.7 & 41.9 & 37.9 & 21.1 & 0.511 \\
\hline $\begin{array}{l}\text { Near complete ability to integrate data, including medication data } \\
\text { from outside providers }\end{array}$ & 9.9 & 3.8 & 15.5 & 21.1 & 0.019 \\
\hline $\begin{array}{l}\text { Near complete ability to provide patients with electronic chart or } \\
\text { discharge information }\end{array}$ & 54.1 & 58.6 & 49.5 & 47.4 & 0.404 \\
\hline
\end{tabular}

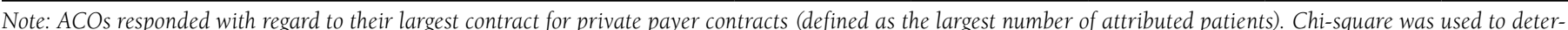
mine significance between ACOs with a private contract, ACOs with a Medicare contract and no private contract, and ACOs with only Medicaid contracts.

aRefers to ACOs whose contracts include commercial as well as Medicare and Medicaid.

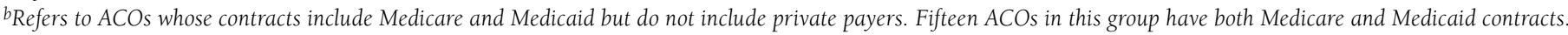
Medicare contracts do not include accountability for pharmacy spending, thus, accountability must come from Medicaid contracts in this subset.

${ }^{c}$ Refers to ACOs whose contracts include only Medicaid and no Medicare or private payer contracts.

$A C O=$ accountable care organization; $E H R=$ electronic health record; IT = information technology.

\section{Results}

Nearly half of ACOs (45.2\%) reported at least 1 contract in which they are accountable for prescription drug spending (Table 1). The proportion of ACOs responsible for prescription spending varied significantly by contract type $(P<0.001)$. More than half of ACOs (76\%) with at least 1 commercial contract were held responsible for pharmacy costs by their largest contract. The Centers for Medicare \& Medicaid Services has 2 ACO programs in place: the Pioneer ACO program (in which providers move more quickly to bearing financial risk) and the Shared Savings Program (where most providers are currently eligible for bonus payments but not bearing financial risk). ${ }^{21}$ Participants in these programs are not responsible for pharmacy spending; these benefits are managed by commercial insurers under Medicare Part D.

Over a quarter of ACOs (26\%) reported having a pharmacy, and $19 \%$ of ACOs reported contracting for pharmacy services (Table 1). ACOs with commercial contracts were more likely to have a pharmacy (31\%) and more likely to have contracted pharmacy services (22\%) than ACOs with Medicare contracts (16\% and $15 \%$, respectively, $P=0.001$ ) and only Medicaid contracts $(50.0 \%$ and $22.2 \%$, respectively, $P=0.001)$.

Health information technology capabilities necessary to manage prescription drug costs and quality were mixed among ACOs (Table 1). Almost half of ACOs (45\%) reported near complete ability to e-prescribe and confirm whether prescriptions have been filled, and 54\% of ACOs maintained an active medication list within the electronic health record. However, only $10 \%$ of ACOs reported near complete ability to integrate inpatient and outpatient data, including medication data, from providers outside the ACO into the electronic health record. Medication-related health information technology capabilities did not differ by contract type (Table 1), ACO characteristics, or pharmacy spending accountability (data not shown).

On average, ACOs that include pharmacies offered a more diverse set of services, were more likely to have both commercial and public contracts, and had greater experience with payment reform (Table 2), when compared with ACOs without formal pharmacy relationships. ACOs that have or contract with an outpatient pharmacy were more likely to have a hospital (83\% of ACOs with a formal pharmacy relationship contained a hospital while just $48 \%$ of those without a pharmacy relationship contained a hospital) and a nursing facility (31\% of ACOs with a formal pharmacy relationship contained a nursing facility while just $9 \%$ of those without a pharmacy relationship contained a nursing facility). In addition, ACOs with a pharmacy relationship were generally larger (more fulltime equivalent physicians) than ACOs without a pharmacy. ACO features positively associated with pharmacy engagement in bivariate analyses included having a greater number of ACO contracts, a contract with a private payer, a two-sided risk contract in the first year, and previous experience with payment reform. Having a contract with Medicare was negatively associated with pharmacy engagement. 
Role of Pharmacy Services in Accountable Care Organizations

TABLE 2 ACO Characteristics and Engagement with Outpatient Pharmacy

\begin{tabular}{|c|c|c|c|}
\hline & \multicolumn{2}{|c|}{ Engagement with Outpatient Pharmacy } & \multirow[b]{2}{*}{$P$ Value } \\
\hline & $\begin{array}{l}\text { Within ACO or Outside Contract } \\
(n=116,45.7 \%)\end{array}$ & $\begin{array}{l}\text { No Formal Relationship } \\
(n=138,54.3 \%)\end{array}$ & \\
\hline \multicolumn{4}{|l|}{ ACO organizational characteristics } \\
\hline Hospital (\%) & 83.3 & 47.7 & $<0.001$ \\
\hline Primary care clinicians (mean, SD) & $245.7 \quad(226.7))$ & $(106.6)$ & $<0.001$ \\
\hline Specialty clinicians (mean, SD) & $317.7 \quad(384.2)$ & $(292.0)$ & 0.002 \\
\hline FQHC or rural health center designation (\%) & 57.5 & 51.5 & 0.359 \\
\hline Nursing facility ownership (\%) & 31.3 & 9.4 & $<0.001$ \\
\hline Integrated delivery system (\%) & 71.0 & 44.2 & $<0.001$ \\
\hline \multicolumn{4}{|l|}{ Contract features } \\
\hline Total ACO contracts (mean, SD) & $(1.4)$ & $(1.2)$ & 0.017 \\
\hline Medicare contract (\%) & 53.4 & 74.6 & $<0.001$ \\
\hline Private contract (\%) & 65.5 & 47.0 & 0.004 \\
\hline Contract with two-sided risk in first year (\%) & 37.1 & 24.2 & 0.031 \\
\hline \multicolumn{4}{|l|}{ Capabilities (\%) } \\
\hline Half or more PCPs attest to meaningful use & 81.8 & 71.3 & 0.282 \\
\hline Strong ability to monitor quality performance & 51.8 & 50.7 & 0.871 \\
\hline Strong ability to monitor financial performance & 35.4 & 30.7 & 0.429 \\
\hline \multicolumn{4}{|l|}{ Previous experience with payment reform (\%) } \\
\hline Bundled or episode-based payments & 41.0 & 30.5 & 0.117 \\
\hline Patient-centered medical home & 92.6 & 81.6 & 0.015 \\
\hline Pay-for-performance programs & 94.7 & 87.9 & 0.067 \\
\hline Publicly report quality measures & 91.6 & 77.8 & 0.004 \\
\hline Other risk-bearing contracts, e.g., capitation & 74.8 & 55.8 & 0.004 \\
\hline Other payment reform effort & 59.2 & 43.4 & 0.052 \\
\hline
\end{tabular}

\section{Discussion}

While Medicare has not included pharmacy spending in its accountable care programs, ACOs with commercial contracts are, for the most part, held responsible for pharmacy spending. More advanced ACOs-those with more payment reform experience, multiple contracts, and a diversity of providers-are the most likely to include a pharmacy. This finding may indicate that these ACOs understand the importance of ensuring effective and efficient prescribing and adherence to achieving quality and cost goals, or that integrated systems with pharmacy services are more likely to take on the risk of new payment contracts.

This analysis allows us to generate hypotheses about the effect of ACO implementation on prescription drug management, including the use of pharmacists as integrated providers of care and other innovative strategies to optimize medical management and possibly reduce total health care spending. We hypothesize that 3 main approaches are likely to emerge as ACOs focus on pharmaceutical use as a way to control spending and improve quality and outcomes. First, some ACOs will incorporate a pharmacy within the ACO but will not emphasize prescription drug management. Rather, by assuming ownership of pharmacy services, these ACOs could lower barriers to necessary medications and encourage use of the most costeffective medications when appropriate through the pharmacy. A second model may be clinician-focused; specifically, ACO administrators will charge clinicians with managing the use of prescription drugs through enhanced care coordination, patient education, enhanced attention to potential drug interactions, and adherence monitoring, particularly for high-risk patients.

Third, some ACOs will broaden the role of pharmacists, integrating pharmacists into patient care. ${ }^{22}$ Evidence suggests that expanding the role of pharmacists is beneficial for total cost and quality. ${ }^{13,23,24}$ Pharmacists can also improve disease management by monitoring and encouraging prescription adherence, making care plan recommendations to the referring provider, and monitoring biometrics, such as blood pressure or glycosylated hemoglobin..$^{15}$ In some cases, pharmacists can be empowered to adjust or initiation medications according to a protocols. ${ }^{25-27}$ Medicare's medication therapy management and quality improvement program is an example of a payer formally recognizing the potential value of such services performed by pharmacists. ${ }^{28}$

Many barriers and obstacles limit the incorporation of pharmacy services into the ACO model. Providers, who have 
contracts with a diverse set of payers, care for patients with an equally or more diverse set of prescription benefits and, perhaps most importantly, preferred pharmacy network and mail order programs. Gaining control of pharmacy services for substantial portions of patients would require an ambitious disruption of well-established prescription payment and benefits structures. Conversely, incorporation of pharmacists' services as part of care coordination (model 3 on previous page) should be relatively seamless but requires recognition of the value of such unreimbursed services and their potential contribution to savings. As providers gain experience with this payment model and as the proportion of patients covered by such payment models increases, we expect these obstacles will be successfully overcome.

Our work is consistent with other preliminary evidence on ACOs and pharmacy services. A study of a small convenience sample of ACOs that examined whether ACOs are equipped to advance appropriate medication use found mixed results. Dubois et al. (2014) concluded that although some ACOs have developed key information technologies to manage prescription drug use, there are critical gaps in their preparedness, and current progress is likely a response to the Medicare electronic health record incentive program, which pays providers to use technology to improve patient care..$^{18}$ The study by Dubois et al. did not evaluate ACO's broader strategies to manage drug use or their accountability for pharmacy spending.

Our analysis provides a first look at the landscape of ACOs and their efforts to engage pharmacies, using data from the first comprehensive national study of the field of ACOs. The accountable care model may represent a new opportunity to promote safe, effective, and appropriate use of prescription drugs while perhaps curbing pharmacy spending in the commercially insured. The Centers for Medicare \& Medicaid Services should consider methods by which Pioneer and Shared Savings Program participants can be held accountable for pharmacy spending. While such accountability will be hindered by the fact that private plans administer Part D benefits, data reported to the Medicare program should permit evaluation of prescription drug use quality and efficiency. Our findings also suggest that while the majority of commercial ACOs are responsible for pharmacy spending, many ACOs may be missing an opportunity to enhance care and perhaps reduce overall cost through richer integration of pharmacist services in care delivery and more effective use of health information technology to manage prescription drugs. ${ }^{22-24}$ Payers, including Medicare, could also hold ACOs responsible for prescribing quality and prescription drug spending.

Further, the transition away from fee-for-service payment may represent an opportunity to integrate pharmacists in patient care. Indeed, Walgreens has taken an important step by being the first national pharmacy chain to orchestrate the development of 3 ACOs, establishing new partnerships between pharmacists and primary care providers. ${ }^{29}$ These ACOs will lead the integration of pharmacy and appropriate drug management in patient care and permit evaluation of pharmacy integration as a quality improvement and cost reduction strategy. Beyond supporting medication adherence, Walgreens' pharmacists monitor patient adherence to a physician's treatment plan and staff in-store clinics. ${ }^{29}$

Refining performance measures to compel ACOs to prioritize the quality and cost of prescription drug use could prove important. Effective measures could incentivize use of the safest and most effective drugs, while incorporating some degree of cost management (e.g., financial penalties for medication errors; rewarding clinicians for pursuing appropriate, cost-effective alternatives to medication; or penalties for use of drugs without proven clinical benefit or risk of harm). ${ }^{17,18}$ Such measures would encourage ACOs to implement a broad program to manage prescription drug use rather than narrow initiatives related to specific intermediate outcomes (e.g., blood pressure).

\section{Limitations}

Our study has some limitations. We assessed nonresponse bias using publicly available data on Medicare ACOs; however, it is difficult to test nonresponse bias in ACOs with a commercial contract, since ACOs were identified through public sources, so there is no means of verifying the true population. Although we attempted to identify the most appropriate survey respondent at each organization, the responding individual may not have had complete information about the level of pharmacy engagement. We believe response bias was minimal, given the high response rate, exhaustive efforts to identify potential ACOs, and pilot test of the survey instrument; however, we cannot measure biases traditionally associated with voluntary surveys.

\section{Conclusions}

The ability of the accountable care model to hold organizations accountable for pharmacy spending and medication management, particularly for patients with multiple chronic illnesses, is likely to be a key factor associated with achieving the triple aim of improving the experience of care, improving the health of populations, and reducing costs. ${ }^{30}$ The present findings provide important baseline information for assessing the innovative approaches to medication management and their progress over time. Further analysis, linking health outcomes measurement to ACO characteristics and capabilities, is needed to assess the performance of ACOs taking varied approaches to prescription drug management. Given the broad implications of prescription drug management on quality and cost, ACOs may choose to improve prescription drug management through additional strategies such as including clinical pharmacists on care teams, assigning "medication coaches" to high medication utilizers, and using various in-home monitoring devices to track adherence. 


\section{Authors}

CARRIE H. COLLA, PhD, is Assistant Professor, The Dartmouth Institute for Health Policy \& Clinical Practice, Geisel School of Medicine at Dartmouth, and Norris Cotton Cancer Center, Dartmouth-Hitchcock Medical Center, Lebanon, New Hampshire. VALERIE A. LEWIS, PhD, is Assistant Professor, and BRENDIN R. BEAULIEU-JONES, is Health Policy Fellow, The Dartmouth Institute for Health Policy \& Clinical Practice, Geisel School of Medicine at Dartmouth, Lebanon, New Hampshire. NANCY E. MORDEN, MD, MPH, is Associate Professor, The Dartmouth Institute for Health Policy \& Clinical Practice, Geisel School of Medicine at Dartmouth, Department of Community and Family Medicine, Geisel School of Medicine at Dartmouth, and Norris Cotton Cancer Center, Dartmouth-Hitchcock Medical Center, Lebanon, New Hampshire.

AUTHOR CORRESPONDENCE: Carrie H. Colla, PhD, 35 Centerra Pkwy., Lebanon, NH 03766; Tel.: 603.650.3521; Fax: 603.653.0896; E-mail: carrie.h.colla@dartmouth.edu.

\section{DISCLOSURES}

This work was supported by grants from The Commonwealth Fund (\#20130084) and the National Institute on Aging-National Institutes of Health (K23AG035030-Morden). The authors have no conflicts to report.

Study concept and design were contributed by Colla and Lewis, along with Shortell and Fisher. Colla and Lewis collected the data, and all authors contributed equally to analysis. The manuscript was written by BeaulieuJones, Colla, Morden, and Lewis and revised by Morden, Colla, Lewis, and Beaulieu-Jones, with assistance from Shortell and Fisher.

\section{ACKNOWLEDGMENTS}

We acknowledge Drs. Elliott S. Fisher and Stephen M. Shortell for their contributions to the study design, analysis, and manuscript preparation.

We also acknowledge the Commonwealth Fund and the National Institute on Aging for supporting this work.

\section{REFERENCES}

1. National Center for Health Statistics. Health, United States, 2011: with special feature on socioeconomic status and health. DHHS Publication No. 2012-1232. May 2012. Available at: http://www.cdc.gov/nchs/data/hus/husll.pdf. Accessed March 2, 2015.

2. The Boards of Trustees, Federal Hospital Insurance and Federal Supplementary Medical Insurance Trust Funds. The 2013 annual report of the Boards of Trustees of the Federal Hospital Insurance and Federal Supplementary Medical Insurance Trust Funds. May 31, 2013. Available at: http://www.cms.gov/Research-StatisticsData-and-Systems/Statistics-Trends-and-Reports/ReportsTrustFunds/Downloads/ TR2013.pdf. Accessed March 2, 2015

3. Donohue JM, Morden NE, Gellad WF, et al. Sources of regional variation in Medicare Part D drug spending. N Engl J Med. 2012;366(6):530-38.

4. Gellad W, Good C, Lowe J, Donohue J. Variation in prescription use and spending for lipid-lowering and diabetes medications in the Veterans Affairs Healthcare System. Am J Manag Care. 2010;16(10):741-50.

5. Munson JC, Morden NE, Goodman DC, Valle LF, Wennberg JE. The Dartmouth atlas of Medicare prescription drug use. The Dartmouth Institute for Health Policy and Clinical Practice, Center for Health Policy Research. October 15, 2013. Available at: http://www.dartmouthatlas.org/downloads/reports/ Prescription_Drug_Atlas_101513.pdf. Accessed March 2, 2015.

6. Zhang Y, Baicker K, Newhouse JP. Geographic variation in Medicare drug spending. N Engl J Med. 2010;363(5):405-09.

7. Cox ER, Motheral BR, Henderson RR, Mager D. Geographic variation in the prevalence of stimulant medication use among children 5 to 14 years old: results from a commercially insured U.S. sample. Pediatrics. 2003;111(2):237-43.

8. Gibson TB, Ehrlich ED, Bagalman JE. Variation in prescription drug cost-sharing among the commercially insured. Am J Pharm Benefits. 2012;4(5):e138-el48. 9. Gellad WF, Donohue JM, Zhao X, et al. Brand-name prescription drug use among Veterans Affairs and Medicare Part D patients with diabetes: a national cohort comparison. Ann Intern Med. 2013;159(2):105-14.
10. Adams AJ, Clark DR, DeLander GE, et al. Report of the AACP task force on patient-centered medical homes and accountable care organizations. Am J Pharm Educ. 2013;77(7):142

11. Kripalani S, Roumie CL, Dalal AK, et al. Effect of a pharmacist intervention on clinically important medication errors after hospital discharge: a randomized trial. Ann Intern Med. 2012;157(1):1-10.

12. Forster AJ, Clark HD, Menard A, et al. Adverse events among medical patients after discharge from hospital. CMAJ. 2004;170(3):345-49.

13. Academy of Managed Care Pharmacy. Pharmacists as vital members of accountable care organizations: illustrating the important role that pharmacists play on health care teams. Updated March 2012. Available at: http://www.amcp. org/WorkArea/DownloadAsset.aspx?id=14916.

14. Aspden P, Wolcott JA, Bootman JL, Cronenwett LR, eds. Preventing Medication Errors: Quality Chasm Series. Washington, DC: The National Academies Press; 2007. 15. Congressional Budget Office. Offsetting effects of prescription drug use on Medicare's spending for medical services. November 2012. Available at: http://www.cbo.gov/sites/default/files/cbofiles/attachments/43741-MedicalOffsets-11-29-12.pdf. Accessed March 2, 2015.

16. National Committee for Quality Assurance. HEDIS 2013. Technical specifications for ACO measures. Available at: http://www.ncqa.org/HEDISQualityMeasurement/ HEDISMeasures/HEDIS2013. aspx. Accessed March 2, 2015.

17. Morden NE, Schwartz LM, Fisher ES, Woloshin S. Accountable prescribing. N Engl J Med. 2013;369(4):299-302

18. Dubois RW, Feldman M, Lustig A, et al. Are ACOs ready to be accountable for medication use? J Manag Care Pharm. 2014;20(1):17-21. Available at: http:// www.amcp.org/WorkArea/DownloadAsset.aspx?id=17476.

19. Amara S, Adamson RT, Lew I, Slonim A. Accountable care organizations: impact on pharmacy. Hosp Pharm. 2014;49(3):253-59.

20. The American Association for Public Opinion Research. Standard defintions: final dispositions of case codes and outcome rates for surveys. 2011. Available at: http://www.esomar.org/uploads/public/knowledge-and-standards/codes-andguidelines/ESOMAR_Standard-Definitions-Final-Dispositions-of-Case-Codesand-Outcome-Rates-for-Surveys.pdf. Accessed March 2, 2015.

21. Berwick DM. Launching accountable care organizations-the proposed rule for the Medicare Shared Savings Program. N Engl J Med. 2011;364(16):e32. 22. Smith M, Bates DW, Bodenheimer TS. Pharmacists belong in accountable care organizations and integrated care teams. Health Aff (Millwood). 2013;32(11):1963-70

23. Chisholm-Burns MA, Graff Zivin JS, Lee JK, et al. Economic effects of pharmacists on health outcomes in the United States: a systematic review. Am J Health Syst Pharm. 2010;67(19):1624-34

24. Chisholm-Burns MA, Kim Lee J, Spivey CA, et al. US pharmacists' effect as team members on patient care: systematic review and meta-analyses. Med Care. 2010;48(10):923-33.

25. Gattis WA, Hasselblad V, Whellan DJ, O'Connor CM. Reduction in heart failure events by the addition of a clinical pharmacist to the heart failure management team: results of the Pharmacist in Heart Failure Assessment Recommendation and Monitoring (PHARM) Study. Arch Intern Med. 1999;159(16):1939-45

26. Montazeri M, Cook DJ. Impact of a clinical pharmacist in a multidisciplinary intensive care unit. Crit Care Med. 1994;22(6):1044-48.

27. Zermansky AG, Petty DR, Raynor DK, Freemantle N, Vail A, Lowe CJ. Randomised controlled trial of clinical medication review by a pharmacist of elderly patients receiving repeat prescriptions in general practice. BMJ. 2001;323(7325):1340-43.

28. Centers for Medicare \& Medicaid Services. Prescription drug benefit manual. Chapter 7, Medication therapy management and quality improvement program. Revised February 19, 2010. Available at: http://www.cms.gov/Medicare/ Prescription-Drug-Coverage/PrescriptionDrugCovContra/Downloads/Chapter7. pdf. Accessed March 2, 2015.

29. Punke H. Walgreens' strategy behind ACO participation. Becker's Hospital Review. February 7, 2013. Available at: http://www.beckershospitalreview.com/ hospital-physician-relationships/walgreens-strategy-behind-aco-participation. html. Accessed March 2, 2015

30. Berwick DM, Nolan TW, Whittington J. The triple aim: care, health, and cost. Health Aff (Millwood). 2008;27(3):759-69. 


\section{APPENDIX National Survey of Accountable Care Organizations Screening Questions, Wave 2}

Below are the set of screening questions used to determine whether a commercial contract constituted an accountable care organization (ACO). Similar questions were asked for Medicare and Medicaid contracts.

[qsla] Do you have or are you pursuing an ACO/ACO-like contract with a commercial payer or private insurance plan at this time?

$\square$ Yes - we currently have an ACO or ACO-like contract (1)

$\square$ Yes - we are pursuing an ACO or ACO-like contract (2)

Not pursuing - but may within the next 12 months (3)

Not pursuing - and do not plan to (4)

[If "qsla" answered "yes - currently have" or "yes - are pursuing" display "qslb"]

[qslb] Under your commercial ACO contract, are you responsible for the cost of care for your patient population (e.g., through withholds, bonuses, shared savings, capitation)?

Y Yes (1)

№ $(0)$

[If "qslb" answered "yes" display "qslc"]

[qslc] Under your ACO contract, are you responsible for quality performance?

○ Yes (1)

No $(0)$

[If "qsla" answered "not pursuing - but may in future" or "not pursuing - and do not plan to" display "qsld"]

[qsld] Are you responsible for the total cost of care for your patient population (e.g., through withholds, bonuses, shared savings, capitation) for any of your contracts with commercial insurance plans?

$\square$ Yes (1)

No $(0)$

[If "qsld" answered "yes" display "qsle"]

[qsle] Under your contract where you are responsible for the total cost of care, are you responsible for quality performance?

$\square$ Yes (1)

No $(0)$

[If answer "yes" to "qsld" and "qsle" display message below]

We consider all contracts that hold organizations responsible for the total cost of care of a defined patient population and for quality performance benchmarks to be ACO contracts. Based on your responses, we consider your organization to have a commercial ACO contract. 